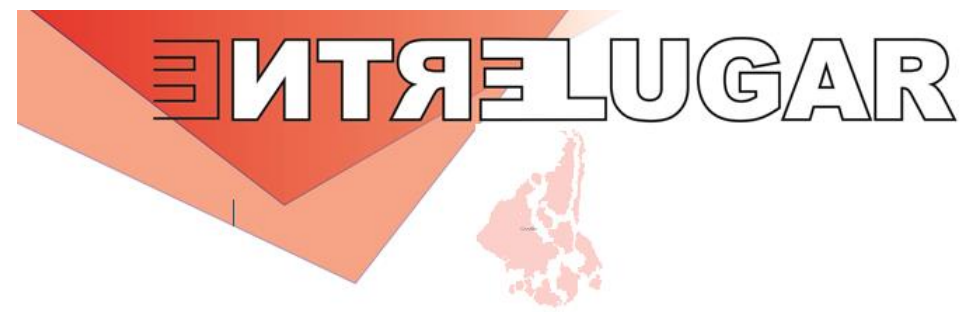

\title{
CONVERGÊNCIAS E CONTRADIÇÕES DO NOVO MAPA DA INDÚSTRIA DE CALÇADOS NO BRASIL ${ }^{1}$ CONVERGENCES AND CONTRADICTIONS OF THE NEW FOOTWEAR INDUSTRY MAP IN BRAZIL CONVERGENCIAS Y CONTRADICCIONES DEL NUEVO MAPA DE LA INDUSTRIA DEL CALZADO EN BRASIL
}

\section{Edilson Pereira Júnior}

Doutor em Geografia pela Unesp - Presidente Prudente. Coordena o Laboratório de Estudos do Território e da Urbanização - LETUr. Docente na Universidade Estadual do Ceará (UECE). Bolsista Produtividade 2 do CNPq.

$$
\text { edilsonapjr@hotmail.com }
$$

\section{José Eudázio Honório Sampaio}

Doutorando do Programa de Pós-Graduação em Geografia da Universidade Estadual do Ceará (UECE). Membro do Laboratório de Estudos do Território e da Urbanização - LETUr.

$$
\text { eudaziosampaio@gmail.com }
$$

\section{RESUMO}

O mais recente arranjo produtivo da indústria de calçados no Brasil resulta de estratégias de desconcentração produtiva, de relocalização de empregos/estabelecimentos e de complexificações materiais e imateriais de interações em rede, cujo movimento não esconde uma nova relação de forças entre os proprietários e seus concorrentes em uma escala cada vez mais ampla. As transformações passam pela incorporação informal de mão de obra barata e pela ampliação de investimentos em territórios onde a produção não era tradicional. O objetivo deste artigo é analisar o significado dessas modificações, ao identificar as características do novo mapa da produção nacional, o que justifica a relação entre território e competitividade, numa escalada da ampliação das margens de lucratividade.

Palavras-chave: Novo mapa da indústria; Produção de calçados; relocalização industrial.

\footnotetext{
${ }^{1} \mathrm{O}$ artigo sistematiza resultados de pesquisas financiadas pela Coordenação de Aperfeiçoamento de Pessoal de Nível Superior (CAPES) e pelo Conselho Nacional de Desenvolvimento Científico e Tecnológico (CNPq).
}

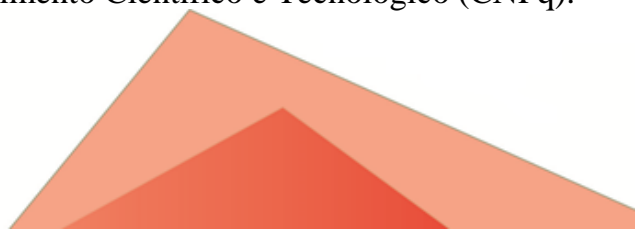




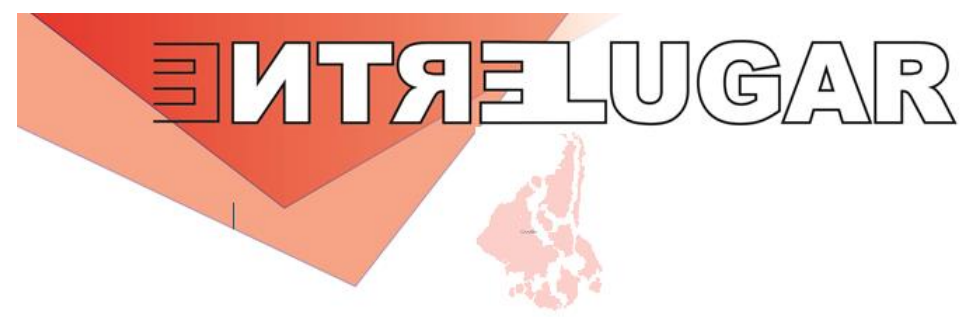

\begin{abstract}
The most recent productive arrangement of the footwear industry in Brazil results from productive decentralization strategies, as well as from relocation of job/factories, and from material and immaterial complexifications of network interactions, whose movement does not hide a new force relationships between the owners and their competitors on an increasingly broad scale. The transformations involves the cheap labor force informal incorporation and the investment expansion in territories where production was not traditional. This article aims to analyze the meaning of these changes by identifying the characteristics of the new national production map, what justifies the relationship between territory and competitiveness, in an increase in the expansion of profitability margins.
\end{abstract}

Keywords: New map of industry; Footwear production; Industrial relocation.

\title{
RESUMEN
}

El arreglo productivo más reciente de la industria del calzado en Brasil es el resultado de estrategias de desconcentración productiva, reubicación de trabajos/establecimientos y complejizaciones materiales e inmateriales de las interacciones de red, cuyo movimiento no oculta una nueva relación de fuerzas entre los propietarios y sus competidores. en una escala cada vez más amplia. Las transformaciones incluyen la incorporación informal de mano de obra barata y la expansión de inversiones en territorios donde la producción no era tradicional. El propósito de este artículo es analizar el significado de estos cambios, identificando las características del nuevo mapa de producción nacional, que justifica la relación entre territorio y competitividad, en una escalada de la expansión de los márgenes de ganancia.

Palabras clave: Nuevo mapa de la industria; Producción de calzado; Reubicación industrial.

\section{INTRODUÇÃO}

Este artigo procura analisar em que medida as transformações materializadas no período da globalização confirmam uma reestruturação espacial na indústria de calçados associada às características da nova economia política do território no Brasil. Entendemos que a mais recente dinâmica deste gênero produtivo no país engendram mudanças a partir

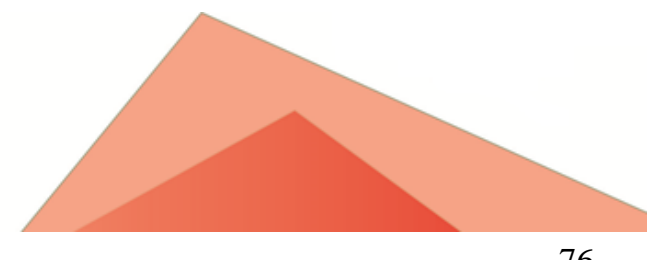


da relação entre o local, o nacional e o global, produzindo um território que revela sua estrutura multidimensional e transescalar, em especial a partir de novas articulações econômicas e políticas.

A escolha pela abordagem territorial da indústria de calçados se dá em função de o processo produtivo neste segmento ser um dos que mais se transforma no Brasil, ao alcançar lugares de reserva e criar relações verticalizadas no espaço. Por envolverem pequenos produtores, mas também agentes empresariais/financeiros ligados ao movimento de acumulação ampliada da globalização, o gênero se apresenta como um dos mais sensíveis às transformações da nova configuração capitalista com predominância financeira (CHASNAIS, 2006), incorporando estratégias de lucratividade, ao mesmo tempo, renovadas e tradicionais.

A indústria de calçados, face ao conjunto da manufatura brasileira, é uma das que mais emprega trabalhadores, recrutados para linhas de produção dentro de fábricas ou subcontratados para a prestação de serviços auxiliares. Como consequência, modifica sobremaneira a realidade local e regional onde se instala. Assim, analisar suas características e seus impactos implica em interpretar importantes aspectos, como por exemplo, aqueles que envolvem:

1) a relação entre a mais recente acumulação capitalista de predominância financeira com toda sorte de reengenharias de produção industrial e de reestruturação produtiva presentes no Brasil;

2) o papel dos lugares de reserva e de suas políticas de atração de investimentos, sobretudo quando estimulam os deslocamentos empresariais;

3) os novos arranjos de redes e fluxos do capitalismo contemporâneo, que se baseiam em complexas interações espaciais engendradas a partir de disjunções funcionais, por meio das quais os sistemas produtivos localizados e as zonas industriais tradicionais renovam suas experiências na atividade manufatureira. 
O estudo da indústria de calçados em sua relação com o território, desse modo, nos permite vislumbrar aspectos renovados das formas de acumulação pautadas nas relações intersetoriais da economia e no uso econômico da política. Isso só é possível porque a leitura dos acontecimentos é feita a partir de uma relação de abordagens que não negligenciam articulações temáticas e escalares, nem uma melhor apreensão dos recursos e dos atributos oferecidos pela dimensão espacial na interpretação das estratégias de acumulação.

Ao considerar todos esses aspectos, este artigo busca retratar o novo arranjo escalar e multidimensional dos circuitos industriais calçadistas no Brasil, assim como, objetiva retratar as características do novo mapa produtivo nacional, marcado por convergências e contradições. Além desta introdução, um segundo item tratará das dimensões políticas, econômicas e técnicas das dinâmicas citadas; um terceiro item apresentará a natureza territorial das transformações, com alusivas representações cartográficas, e um item conclusivo fará a sistematização das principais ideias trabalhadas.

\section{AS NOVAS ESTRATÉgIAS PRODUTIVAS DA INDÚSTRIA DE CALÇADOS: REDES, DISJUNÇÕES, RELOCALIZAÇÕES}

A produção de territórios engendrados a partir de dinâmicas econômicas definidas pela indústria de calçados no Brasil se dá por meio de relações históricas, mas também pelas novas determinações políticas e econômicas do presente. $\mathrm{O}$ mais recente arranjo escalar e multidimensional dos circuitos calçadistas definem estratégias, objetos e normas e isso resulta numa configuração industrial por meio da qual a concentração produtiva, a relocalização de empregos e estabelecimentos e a complexidade das interações materiais e imateriais se ampliam.

O significado dessas modificações para a indústria de calçados é importante e compõe um quadro de estruturação da produção no Brasil. Ele não foge ao movimento

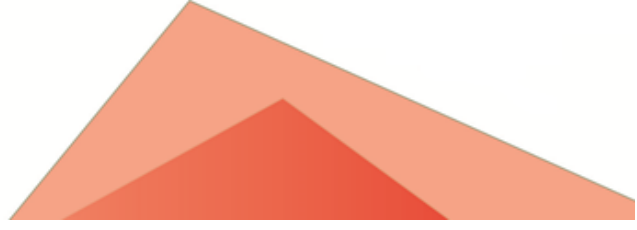


global que estabelece uma nova relação de forças entre os proprietários e seus concorrentes, que intensifica uma competitividade acirrada por taxas de lucratividade amplamente favoráveis, não sem modificar as formas de organização produtiva e de comercialização do produto final fabricado pelas empresas.

Para o Brasil é um movimento que se inicia mais intensamente após a abertura econômica aos investidores internacionais na década de 1990, quando a indústria de calçados sente as consequências do aumento das importações de produtos estrangeiros, e reage ampliando sua produção para o mercado internacional. Isso não poderia ser feito sem que os ganhos de produtividade compensassem a ampliação dos investimentos em máquinas e equipamentos. Ademais, a indústria calçadista é intensiva em mão de obra, portanto parte dos custos de produção está ligada ao preço do trabalho pago em linhas de montagem na fábrica ou através de acordos de subcontratação de trabalhadores.

A indústria então, racionalizou os custos aproveitando medidas de reestruturação, ao mesmo tempo, produtiva e territorial. Produtiva, no sentido de incorporar conquistas gerenciais e tecnológicas, principalmente na absorção de novas formas flexíveis de mecanização e controle efetivo sobre a produção e o trabalho. Territorial, graças às possibilidades de fragmentar a produção no espaço geográfico, introduzindo planos de engenharia não mais comprometidos pela variável distância, aproveitando vantagens regionais e locais anteriormente desconhecidas e eliminando problemas com a pressão sindical ou com a ociosidade de estoques, máquinas e componentes.

Consequentemente, em meados da década de 1990, as maiores empresas brasileiras de calçados entraram em profundo processo de transformação de sua base estrutural, produtiva e operacional. Elas anunciaram que eram principalmente duas as razões das transformações:

1) as margens de rentabilidade da indústria não atendiam mais aos interesses dos investidores, principalmente em razão de alterações estruturais na economia e da maior competitividade internacional com empresas calçadistas de países asiáticos.

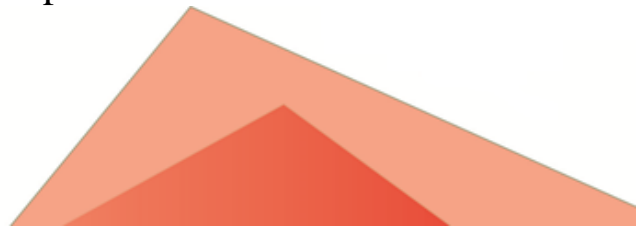


2) as mudanças tecnológicas e produtivas das últimas décadas se apresentaram como estratégias necessárias de organização flexível na busca de mais lucratividade, o que estimulou diferentes práticas de engenharia na produção e novas formas de contratação e subcontratação da mão de obra, levando a uma maior divisão territorial das etapas do processo produtivo.

Como estratégia de redução de custos, os grandes grupos industriais e empresas de médio e grande porte investiram na implantação de unidades produtivas em diversos estados brasileiros, na procura de novas condições de produtividade que fortalecessem as organizações perante os desafios da globalização da economia. Configurou-se assim, um novo mapa locacional da indústria calçadista, marcado pela redistribuição das unidades de produção, tradicionalmente concentradas nos estados de São Paulo e do Rio Grande do Sul, em direção a outras regiões do país, sobretudo o Nordeste, onde a instalação de zonas de produção foi realizada sem, no entanto, comprometer a centralidade de gestão dos estados tradicionais, em especial os centros paulistas de produção (Franca, Jaú e Birigui) e a região do Vale dos Sinos (RS).

Há um duplo aspecto nessa reestruturação, como destacam Costa e Fligespan (2013). O primeiro deles se baseia nos avanços da microeletrônica e na inserção das tecnologias da informação, que criam vantagens competitivas às empresas. Um exemplo são as tecnologias Computer Aided Desig (CAD) e Computer Aided Manufacturing (CAM), ou ainda outros produtos que tornam as empresas mais flexíveis e, neste sentido, mais competitivas. O segundo aspecto trata da organização do trabalho, que se afasta de práticas tayloristas-fordistas e intensifica a prática ligada às formas flexíveis, como o JustIn-Time, os círculos de controle de qualidade, a polivalência, entre outros, ao buscarem minimizar os custos de produção e o desperdício.

A consequência disso é que o número de trabalhadores em linhas de produção se reduz e ocorre uma difusão de equipamentos e a introdução da microeletrônica no processo produtivo. As mudanças também exacerbam a precarização do trabalho, sobretudo

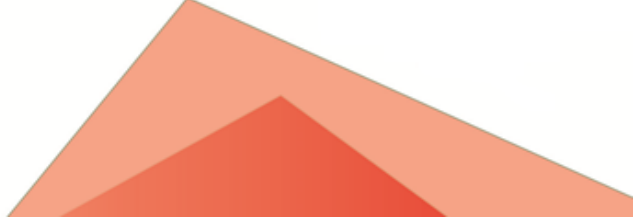


por essa indústria concentrar baixo índice de mecanização e contratar muita mão de obra barata (NAVARRO, 2004). Além disso, há uma redução de empregos formais e no número de trabalhadores nas fábricas, em função de uma maior externalização de etapas produtivas. Isso amplia a informalidade, a dispersão de unidades fabris menores e a falência de vários estabelecimentos. Também ocorre desintegração vertical da produção, em conjunto com a utilização das formas de gerenciar o trabalho, inclusive no território, levando a um novo mapa produtivo da indústria calçadista no Brasil.

\section{TERRITÓRIO E COMPETITIVIDADE NA NOVA CARTOGRAFIA DA INDÚSTRIA CALÇADISTA BRASILEIRA}

A indústria de calçados no Brasil apresenta aproximadamente 7,1 mil estabelecimentos, que geram cerca de 279 mil empregos. Ela tem capacidade instalada estimada em 908,9 milhões de pares/ano, sendo 70\% destinados ao mercado interno e 30\% à exportação para 157 países (ABICALÇADOS, 2018a). Esses números fizeram com que o Brasil estivesse até 2014 no posto de terceiro maior produtor mundial (com produção de cerca de 981 milhões de pares), mas a partir de 2018 passou a ocupar a quarta posição, sendo superado pelo Vietnã em 2015 (a produção brasileira chegou a baixar para 904 milhões de pares). Este último país, junto com China e Índia, são responsáveis por $72 \%$ da produção mundial (ABICALÇADOS, 2018b).

O movimento representou perda de competitividade para essa indústria no Brasil, pois a produção mundial cresceu $10 \%$ nos últimos quatro anos, chegando na marca de 23 bilhões de pares de calçados produzidos (WORLD SHOE REVIEW, 2017) e, enquanto isso, no mesmo período, o país perdeu $7,3 \%$ da sua capacidade produtiva, chegando a 909 milhões de pares fabricados (ABICALÇADOS, 2018b).

As transformações engendradas passam pela incorporação informal de mão de obra barata e pela ampliação de investimentos em territórios onde a produção não era

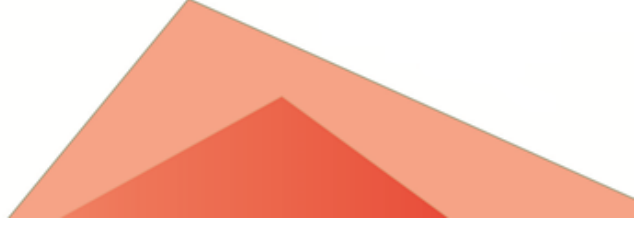


tradicional. As novas estratégias competitivas fazem uso da flexibilização do processo global de produção e da diferenciação espacial, não sem que ocorra incorporação tecnológica avançada durante o processo e que a inovação nos meios de comunicação e transporte possibilitem articulação em rede dos processos produtivos.

Deparamos com o redesenho do mapa da produção, a partir de uma articulação transescalar e multidimensional, o que justifica a relação entre território e competitividade, que culmina com a ampliação da lucratividade da indústria calçadista brasileira. Novos elementos são acrescentados à hierarquia dos espaços do mandar e do fazer (SANTOS, 2002) e em sobreposição à maior concentração produtiva e exportadora do Rio Grande do Sul e de São Paulo, os estados de produção mais tradicionais, alguns estados do Nordeste do Brasil recebem linhas de produção e ampliam sobremaneira sua participação no conjunto da participação nacional.

Como destaca Reis (1994), a indústria de calçados brasileira, com predominância de pequenas e médias empresas, capital nacional e, em geral, de propriedade familiar, tem origem a partir das atividades desenvolvidas no início do século XIX pelos imigrantes alemães e italianos, de maneira artesanal e rudimentar. Além disso, esta produção foi, por muito tempo, um subproduto realizado em pequena escala e fabricada por artesãos, o que demarcou as características da produção no Vale do Rio dos Sinos (RS), na região de Franca (SP) e no estado do Rio de Janeiro.

O pioneirismo da produção no Vale dos Sinos (RS) e em Franca (SP) também pode ser justificado por fatores como matéria-prima disponível (o couro), habilidade dos imigrantes (mão de obra qualificada) e proximidade de mercados de consumo mais dinâmicos. No entanto, isso não significava ausência de produção em outros estados, uma vez que Minas Gerais (Nova Serrana, Belo Horizonte e Uberaba), Pernambuco (Recife), Santa Catarina (São João Batista), Paraná (Curitiba) e Ceará (Juazeiro do Norte e Crato) apresentavam alguns sistemas industriais localizados com produção tradicional.

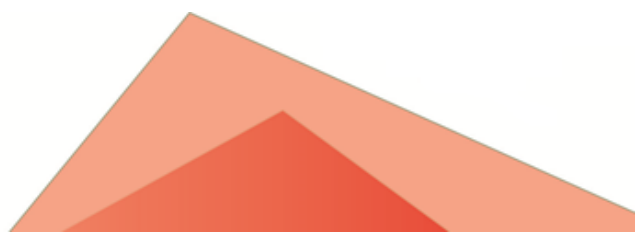


Mas foram os aglomerados industriais já citados do Rio Grande do Sul e de São Paulo que ganharam relevância pela capacidade produtiva e aperfeiçoamento do maquinário e do produto, além da maior escala de fabricação e comercialização, concentrando grande parte dos estabelecimentos industriais, vínculos empregatícios, conhecimento técnico, produção e exportação dos calçados no país.

Uma visão processual das informações sobre o número de estabelecimentos e de vínculos empregatícios da indústria calçadista entre os anos de 1990 e 2017, como representados pelas Figuras 1 e 2, revelam a natureza territorial das mudanças relatadas. Mesmo que no número de estabelecimentos os efeitos não tenham sido representativos (no caso do Rio Grande do Sul o número de estabelecimentos, inclusive, cresce), os cartogramas revelam que a taxa de empregos gerados aumenta significativamente nos novos estados a concentrar a produção.

O fato é que, mesmo para os estabelecimentos, a expansão sentida pelo Rio Grande do Sul (passou de 1.857 para 2.762 unidades de produção entre os anos de 1990 e 2017) é conduzida por pequenas empresas, enquanto as grandes tendem a aprofundar o processo de relocalização das linhas de produção. Ora, são estas empresas as que mais contratam funcionários na fabricação de calçados, e isso explica por que há tanta disparidade na representação de dispersões e concentrações por estados quando comparamos a Figura 1 com a Figura 2.

Assim, face ao quadro geral, ao analisar os vínculos empregatícios entre 1990 e 2017, ambos os estados tradicionais perdem representatividade no país em relação aos novos estados do Nordeste que ampliaram sua produção, leia-se Ceará, Bahia e Paraíba. São Paulo perde 38\% (passa de 61.890 para 38.338) dos vínculos empregatícios e o Rio Grande do Sul perde 25\% (passa de 122.661 para 91.973). 


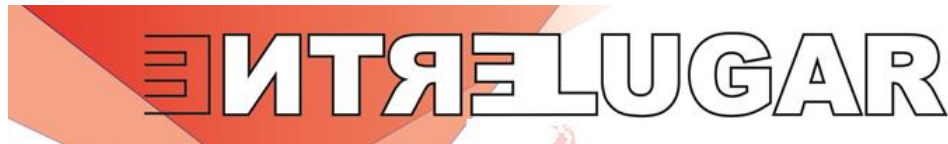

Figura 1 - Distribuição espacial no Brasil de estabelecimentos da indústria de calçados (1990 e 2017)

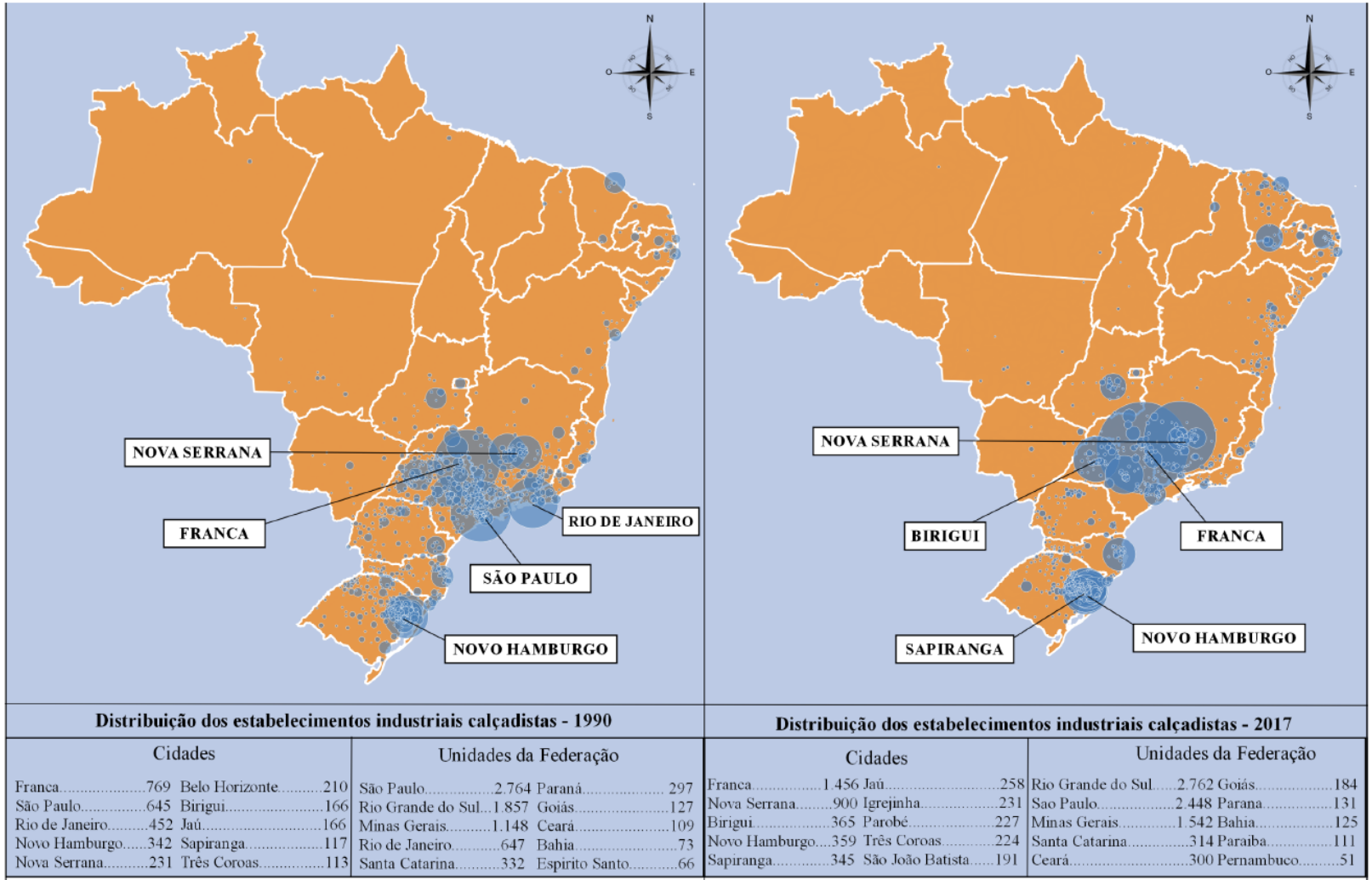

Fonte: Ministério do Trabalho e Emprego (MTE)/Relação Anual de Informações Sociais (RAIS). Elaboração: SAMPAIO, José Eudázio H.

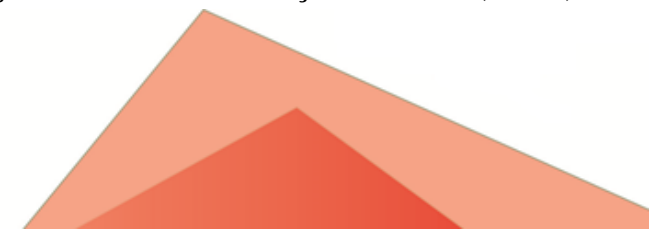




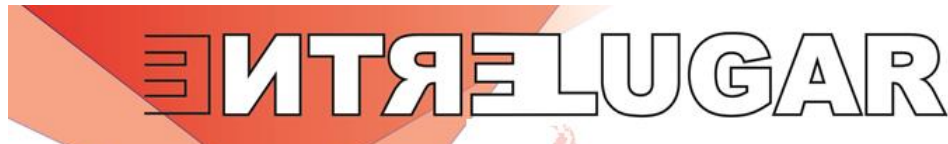

Figura 2 - Distribuição espacial no Brasil de vínculos empregatícios da indústria de calçados (1990 e 2017)

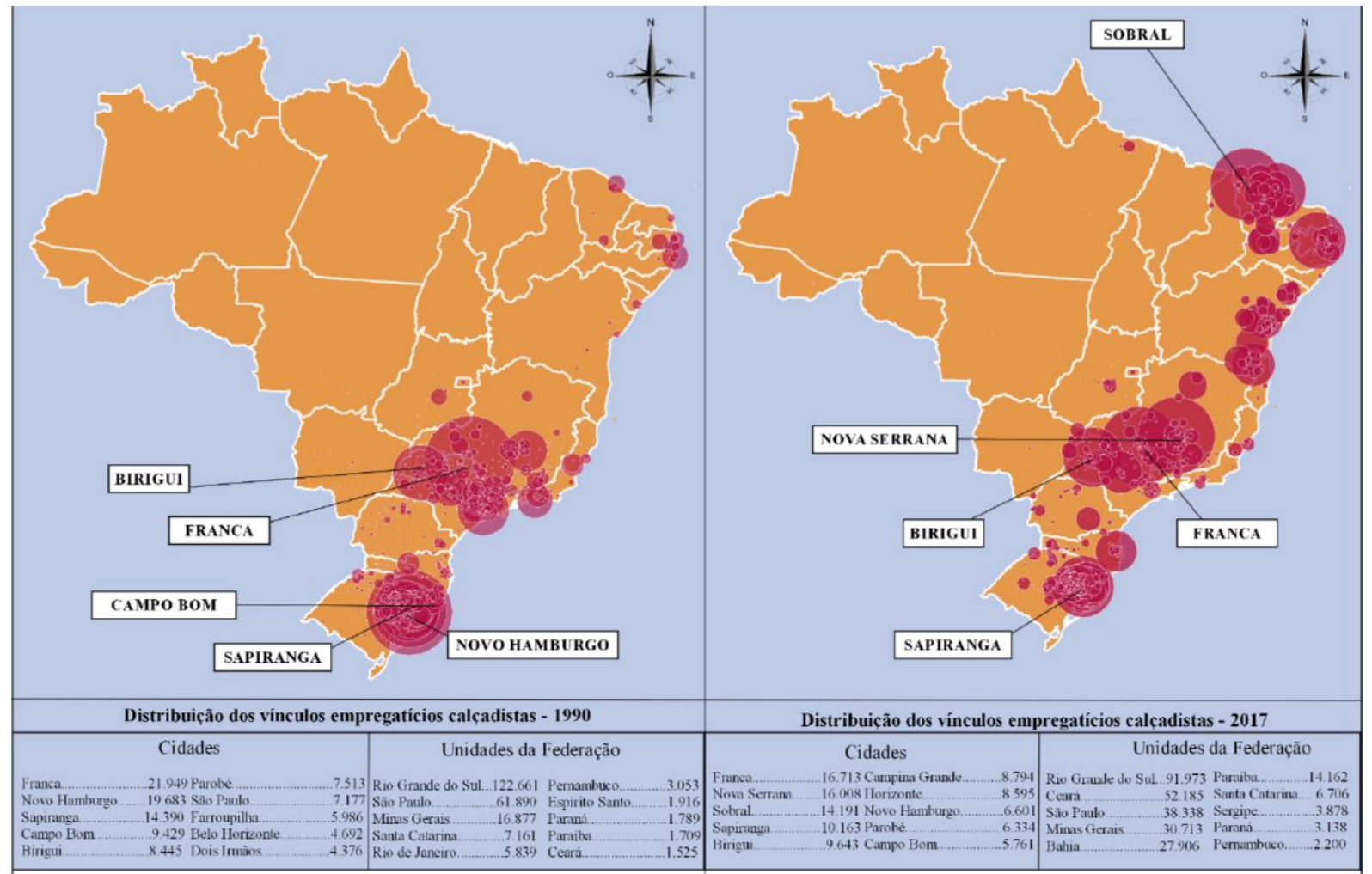

Fonte: Ministério do Trabalho e Emprego (MTE)/Relação Anual de Informações Sociais (RAIS).Elaboração: SAMPAIO, José Eudázio H.

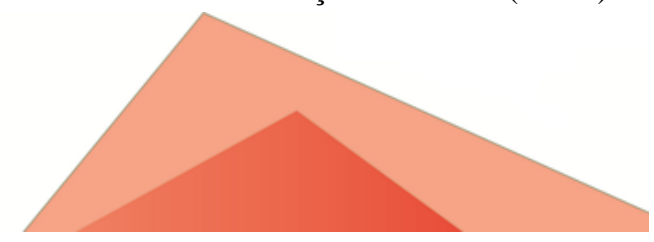


É importante reiterar que, mesmo com a diminuição de estabelecimentos e empregos gerados, houve nos estados tradicionais da produção calçadista uma ampliação dos estabelecimentos industriais de micro e pequeno porte, enquanto médios e grandes diminuíram. Neste caso, devem ser consideradas as microempresas surgidas com as possibilidades de subcontratação, terceirização e maior flexibilização produtiva. Assim, mesmo com a permanência de algumas importantes empresas paulistas e gaúchas em seus estados de origem, que muitas vezes mantêm etapas de comando e gestão, há a presença marcante dos estabelecimentos que não deixam os indicadores desses estados caírem. Eles pertencem às firmas menores, exatamente aquelas que não têm poder de deslocamento geográfico.

É dessa maneira que os sistemas industriais localizados da produção tradicional resistem. Ao fazerem uso de inúmeras estratégias, eles concentram empresas que praticam a disjunção funcional e criam redes produtivas entre diversas fábricas, inclusive as que não estão formalizadas. Estas, por sua vez, são invisíveis nos dados fornecidos pela RAIS/CAGED, o que sugere que os sistemas localizados de centros produtivos em São Paulo e Rio Grande do Sul são bem maiores do que os indicadores tendem a apresentar.

No que tange aos novos centros de produção, o Nordeste brasileiro é o grande foco dos empresários calçadistas para relocalização de unidades produtivas, devido às enormes possibilidades de obtenção de lucros. Como destacam Costa e Fligenspan (2013), a busca pelo Nordeste se deu inicialmente pelas empresas que buscavam atender ao mercado daquela região e, logo em seguida, pelas empresas que buscavam atender ao mercado externo, exatamente num momento de recuperação da competitividade perdida. Assim, ao se apropriarem dos espaços de reserva e estabelecerem um novo mapa da produção, a indústria de calçados se expandiu principalmente para o Ceará, a Paraíba e a Bahia.

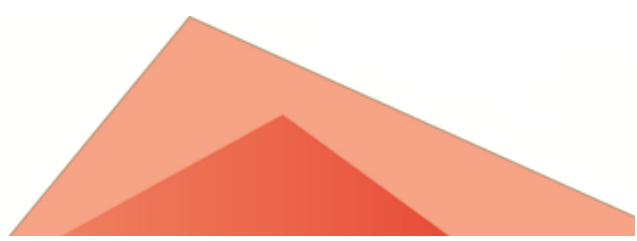




\section{MU}

Estes estados reuniram um conjunto de virtualidades no momento de crise da produção calçadista, em especial porque contaram com a colaboração de políticas públicas de incentivo à produção, tanto de prefeituras como de governos estaduais. Podemos citar, entre os benefícios, o financiamento do Imposto sobre Circulação de Mercadoria e Serviços (ICMS), as isenções de impostos municipais, os benefícios concedidos à exportação através do empréstimo automático correspondente ao percentual do Free on Board (FOB), a isenção de Imposto de Renda, bancado pela União, e as garantias de infraestrutura mínima de instalação, além de outras importantes medidas auxiliares na redefinição da divisão territorial da produção calçadista nacional. São vantagens que atraíram as principais empresas calçadistas do país, que encontraram nesses ambientes as demandas necessárias para garantir produção com competividade, tanto para o mercado nacional como para o internacional.

A Paraíba, por exemplo, até o final da década de 1990, possuía produção pautada em materiais sintéticos e representava $15 \%$ do total de estabelecimentos da região Nordeste, com menos de $1 \%$ do total nacional (51). Com a chegada da empresa Alpargatas e de outras advindas das regiões Sul e Sudeste, a representação cresceu consideravelmente e em 2017 o estado concentrou 111 unidades produtivas, apresentando crescimento de $117 \%$ em 27 anos. Ao analisarmos, porém, seu número de vínculos empregatícios ativos, percebemos um crescimento de $728 \%$, chegando a 14.162 empregos formais (5\% do total nacional).

Enquanto isso, na Bahia, o movimento se fez a partir da chegada de grandes empresas, o que implicou em importantes mudanças no território do estado, em especial no que diz respeito ao número de vínculos empregatícios gerados e à configuração urbanoregional de ocupação das fábricas. Algumas empresas tiveram papel chave para essa mudança nos primeiros anos, como a Vulcabrás/Azaleia, Dass, Via Uno, Grendene, ou ainda, após a saída de algumas delas, a chegada de outras, como a FreeWay e Ferracini

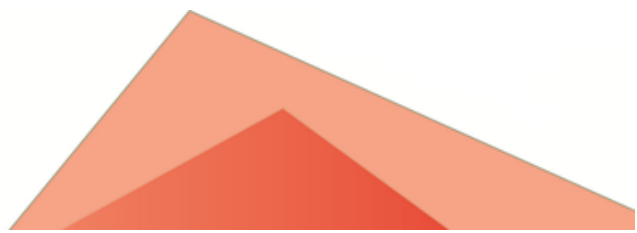




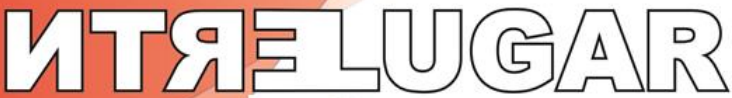

(oriundas de Franca); e as empresas oriundas de Santa Catarina, que ocuparam galpões deixados pela Vulcabrás/Azaleia. Como podemos observar nas Figuras 1 e 2, a Bahia apresentou expansão de 28\% no número de estabelecimentos entre 1990 e 2017 (passou de 73 para 125), enquanto o número de vínculos empregatícios formais saltou consideravelmente, com o estado passando de 331 empregos gerados para 27.906, crescendo $8.972 \%$.

O destaque, entre os estados do Nordeste é o Ceará. Os governos estaduais, com a finalidade de atrair capitais produtivos, criaram o Fundo de Desenvolvimento Industrial do Ceará (FDI), que contribuiu decisivamente no aporte de empresas. Ainda na década de 1990, outros programas foram criados e incentivaram a difusão espacial da indústria, fazendo com que diversos municípios pudessem receber fábricas calçadistas. Em 1990, o Ceará era responsável por deter 1,4\% (109) dos estabelecimentos de calçados do Brasil. Em 2017, o estado apresenta um número de 300 estabelecimentos, ou seja, um crescimento de $175 \%$ em 27 anos (3,6\% do total nacional). No entanto, quando tratamos dos vínculos empregatícios, a expansão foi muito mais expressiva. Em 1990, o Ceará era responsável por empregar $0,6 \%$ do total de trabalhadores do Brasil, ou seja, um total de 1.525 vínculos formais. Já no ano de 2017, essa mesma variável cresceu 3.421\%, chegando a 51.185 vínculos formais, isto é, $19 \%$ da totalidade do país.

Outro indicativo que comprova o deslocamento, no território brasileiro, dos grandes grupos empresariais e das médias empresas calçadistas é a relação entre as empresas exportadoras por estado para os anos de 1997 e 2017, como destacado nas Figuras 3 e 4. Em 1997, o número de empresas exportadoras calçadista era de 490 (Figura 3), concentradas nos estados do Rio Grande do Sul (249), único a representar a faixa "Acima de 40\%" das exportações no país. Enquanto isso, o estado de São Paulo estava representado na faixa "Entre 30\% e 40\%", conformando 35\% (172) de empresas exportadoras. Os outros estados estavam na faixa de "Até 5\%", tais como Minas Gerais

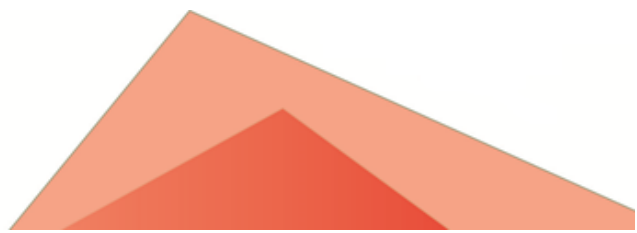




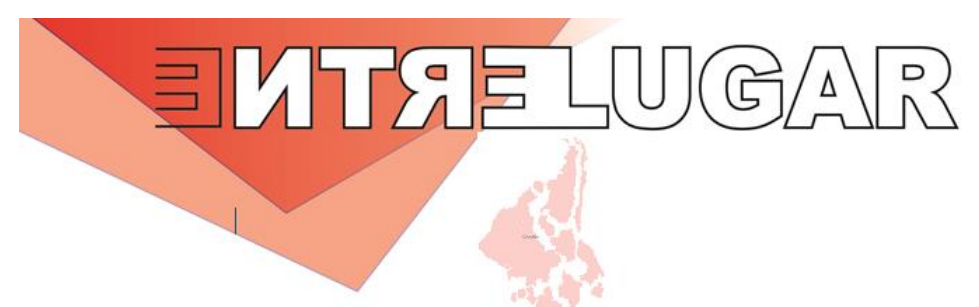

(19), Santa Catarina (18) e Ceará (17), com cerca de $4 \%$ cada. Por fim, a Paraíba correspondia a 1\% (6 empresas) e os estados do Paraná (4), Tocantins (1), Rio Grande do Norte (1), Sergipe (1), Espírito Santo (1) e Rio de Janeiro (1), apresentavam menos de 1\% das empresas exportadoras.

Em 2017, o número total de empresas exportadoras sobe para 503, sendo que o Rio Grande do Sul e São Paulo apresentam uma diminuição ao longo dos últimos 27 anos. O primeiro representava em 1997 mais de 50\% das empresas exportadoras, e em 2017 revela queda de $31 \%$ (de 249 para 170), passando a ocupar uma faixa entre $30 \%$ e $40 \%$ (36\% das empresas exportam). Por sua vez, São Paulo apresentou diminuição de 24\% (de 172 para 131 empresas), ocupando a faixa entre $20 \%$ e $30 \%$ (28\% do total de empresas exportam). 


\section{구ำ}

Figura 3 - Concentração de empresas exportadoras de calçados por Unidade da Federação (1997)

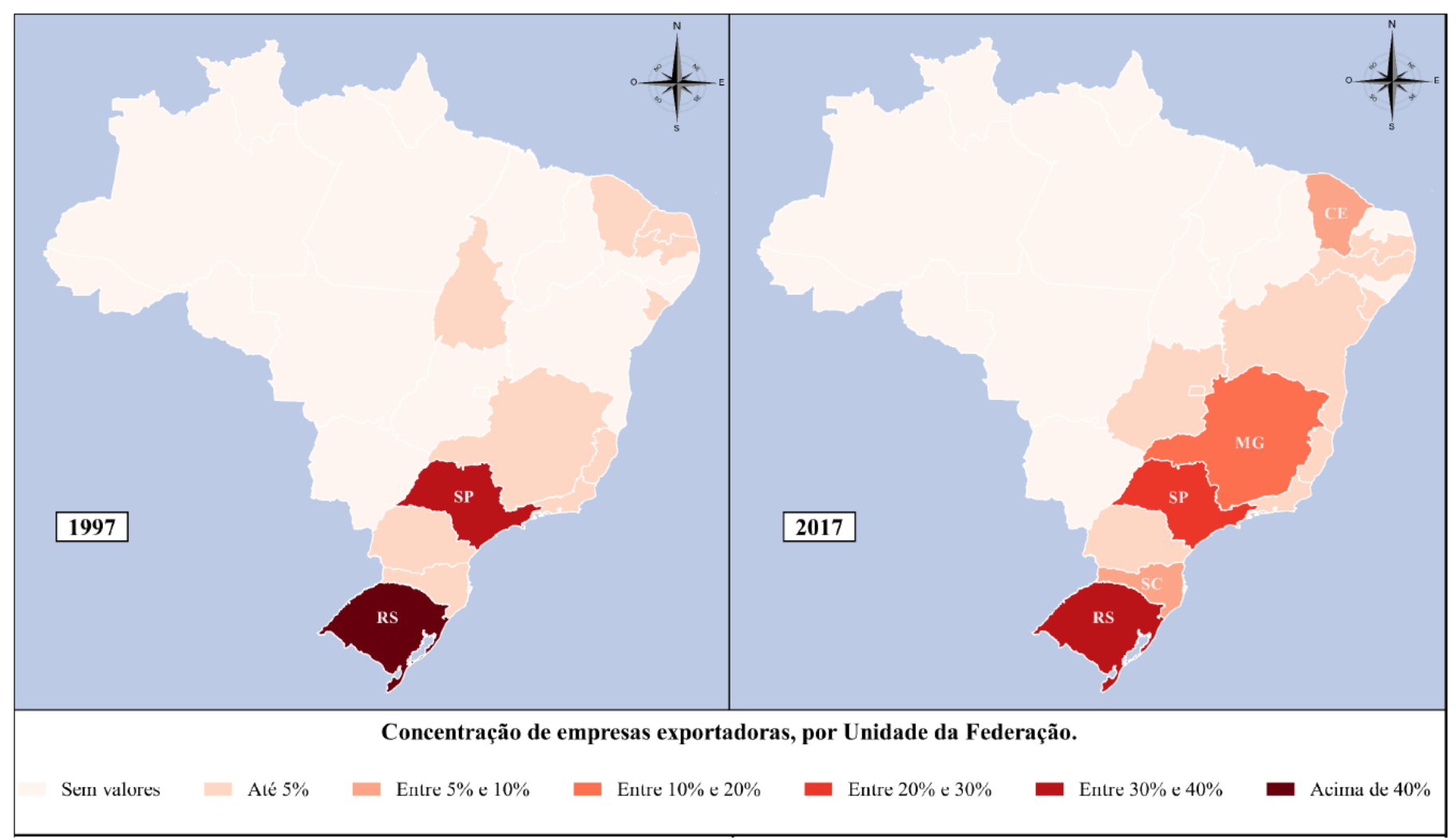

Fonte: Ministério do Desenvolvimento, Indústria e Comércio (MDIC)/SECEX, 2018. Elaboração: SAMPAIO, José Eudázio H.

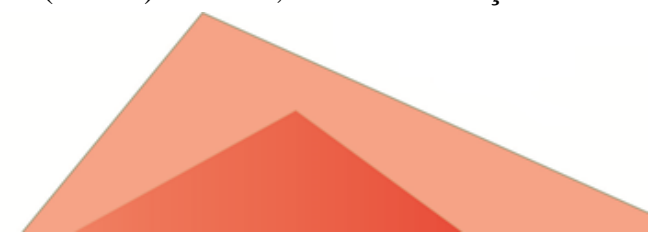




\section{-}

Figura 4 - Concentração de empresas exportadoras e exportação de calçados em pares e em valor arrecadado (US\$), por Unidade da Federação (2017)

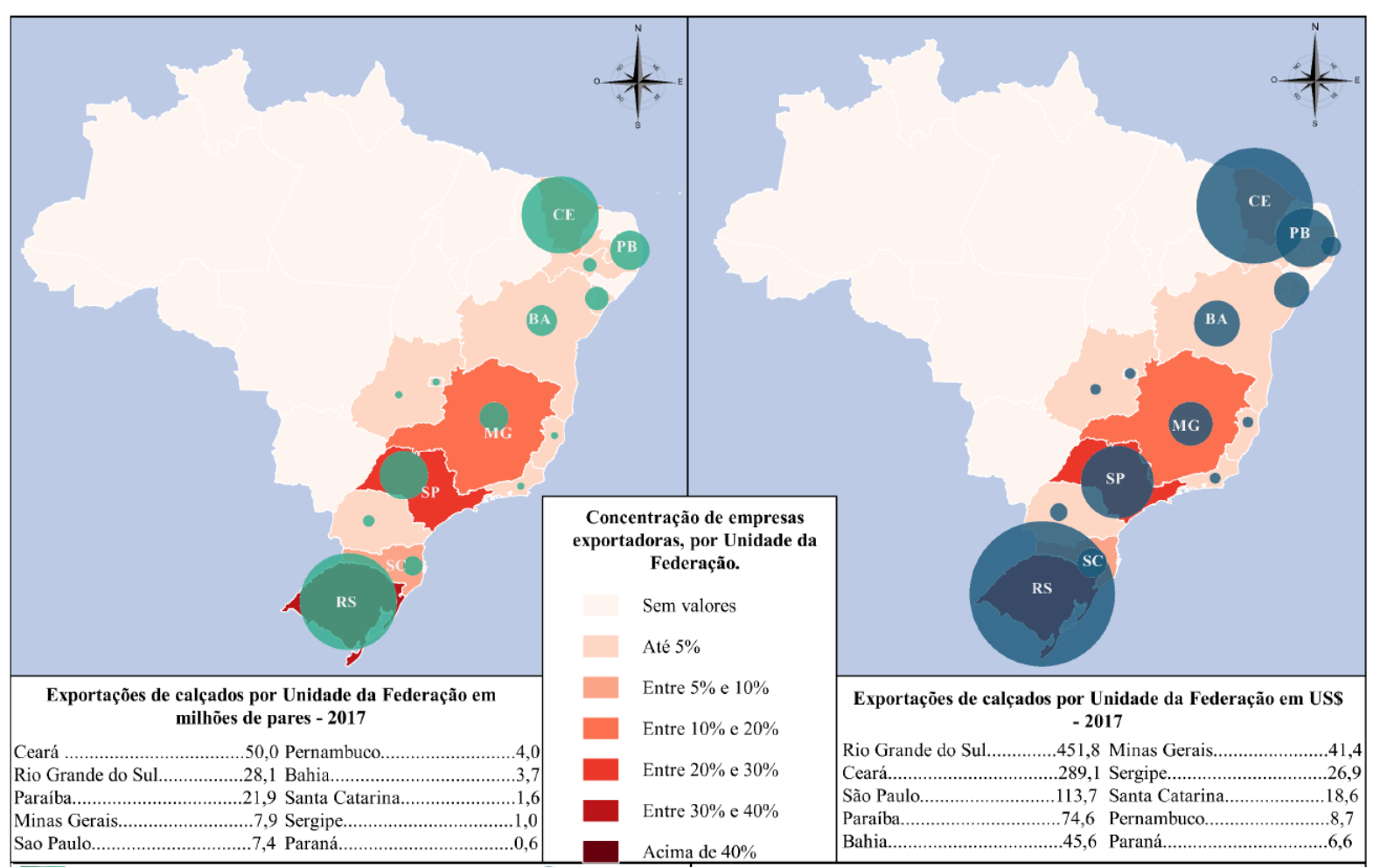

Fonte: Ministério do Desenvolvimento, Indústria e Comércio (MDIC)/SECEX, 2018. Elaboração: SAMPAIO, José Eudázio H.

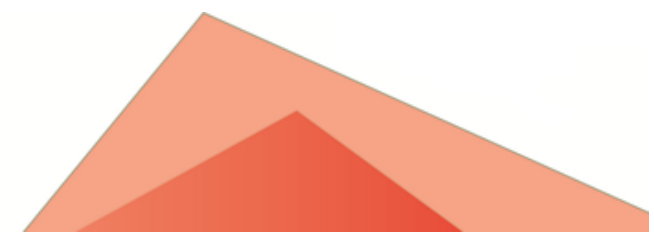




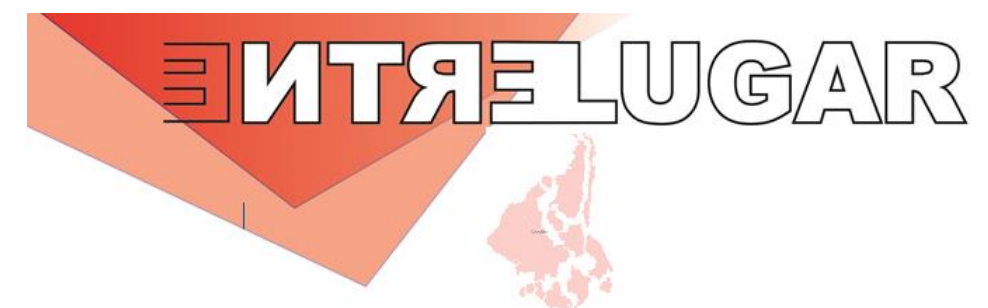

Em 2017 é possível verificar o crescimento significativo dos estados do Nordeste que concentram empresas exportadoras de calçados, e o mesmo acontece com Santa Catarina e Minas Gerais. Por exemplo, o Ceará, que em 1997 representava 4\% do total de empresas exportadoras, passou para a faixa entre 5\% e 10\%, saindo de 17 para 26 empresas que exportam no período analisado. A Bahia, por sua vez, que em 1997 não apresentava nenhuma empresa exportadora, passa a representar $4 \%$ do total (na faixa de até 5\%), com 17 empresas, um crescimento de $1.700 \%$. O estado de Minas Gerais, em 1997, estava na faixa de "Até 5\%" e em 2017 se encontra "entre 10\% e $20 \%$ ", com um total de $15 \%$ das empresas exportadoras. Cresceu $300 \%$ no período e concentra 78 unidades realizando esse comércio internacional, a maior parte delas localizada no município de Nova Serrana e região de influência. Em seguida, temos Santa Catarina, que em 1997 possuía cerca de 4\%, e passa a concentrar, em 2017, 7\% (35 empresas) do total, ou seja, um crescimento de 94\% em 27 anos.

Para além da análise mais quantitativa da concentração das empresas calçadistas exportadoras, interessa uma leitura qualitativa da desconcentração existente, principalmente a partir da quantidade de pares exportados e valor arrecadado, como mostra a Figura 4. Até aqui, percebemos que os estados do Sul e Sudeste tenderam a desconcentrar suas atividades produtivas em direção ao Nordeste, sobretudo as grandes empresas com produção voltada ao mercado externo. Todavia, eles ainda possuem grande contingente de mão de obra empregada e de estabelecimentos industriais, o que torna o papel dos sistemas industriais localizados tradicionais de São Paulo e Rio Grande do Sul muito importante, em especial por manterem sua produção.

Isso nos estimula a constatar que foram as grandes empresas ligadas à produção de calçados fabricados com material sintético que realizaram a disjunção funcional das atividades pelo território nacional. Ao analisarmos os dados de exportação por unidade da federação e os cruzarmos com a concentração de empresas exportadoras, a constatação fica mais evidente. Os estados tradicionais (Rio Grande do Sul e São Paulo) desconcentram a produção das empresas maiores, que atendem tanto ao mercado interno quanto ao mercado externo, e utilizam o Nordeste brasileiro como plataforma de

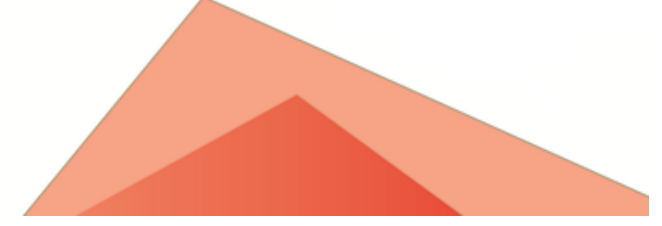




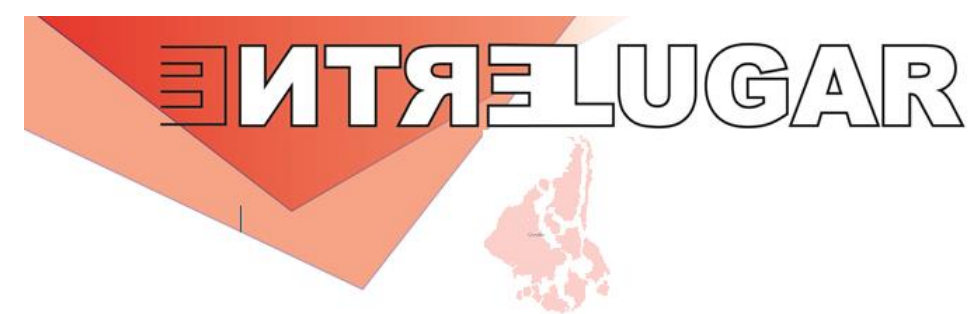

exportação. Assim, há um descompasso entre a concentração de empresas exportadoras e o valor arrecadado/pares exportados, especialmente no que diz respeito aos estados nordestinos.

O Ceará, que concentra $5 \%$ das empresas exportadoras, foi o maior exportador em pares de calçados no ano de 2017, ao exportar um total de 50,0 milhões de pares. Além disso, foi o segundo maior estado em valor arrecadado, ao contabilizar US\$ 289,1 milhões. Enquanto isso, o Rio Grande do Sul, que concentra 36\% das empresas exportadoras, contabilizou no último ano cerca de 28,1 milhões de pares exportados, ficando atrás do Ceará nesta variável. Por outro lado, foi o primeiro em valor arrecadado, acumulando US\$ 451,8 milhões.

O estado de São Paulo, que concentrou em 2017 28\% das empresas exportadoras, ocupa a terceira posição em valor arrecadado nas exportações, com US\$ 113,7 milhões. Mas ocupa a quinta posição em pares exportados, ao comercializar com o mercado exterior pouco mais de 7,4 milhões de pares. Na contramão, temos o estado da Paraíba, que concentra menos de $2 \%$ do total de empresas exportadoras, mas ocupa o terceiro lugar em pares exportados, perfazendo 21,9 milhões de pares e ocupando a quarta posição em valor arrecadado, com US\$ 74,6 milhões em 2017, sobretudo pela participação exercida pelo Grupo Alpargatas.

Em seguida, a Bahia, que concentra apenas 5\% das empresas exportadoras, mas ocupa a quinta posição em valor arrecadado (com US\$ 45,6 milhões), é o sétimo estado em pares exportados, com um total de 3,7 milhões. Já Minas Gerais, que concentra $15 \%$ das empresas exportadoras, se apresenta como o sexto estado em valor arrecadado, com cerca de US\$ 41,4 milhões e a quarta posição em exportação.

Sergipe é um dos mais recentes estados a entrar no mapa da produção calçadista. Ao concentrar apenas três empresas, a Dakota, em Simão Dias, a Vulcabrás/Azaleia, em Frei Paulo e a West Coast, em Nossa Senhora Aparecida, ocupa a sétima posição em 2017, arrecadando um total de US\$26,9 milhões e exportando 1

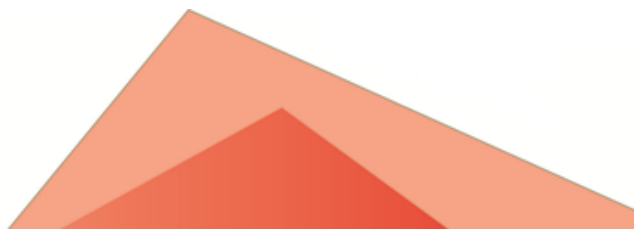




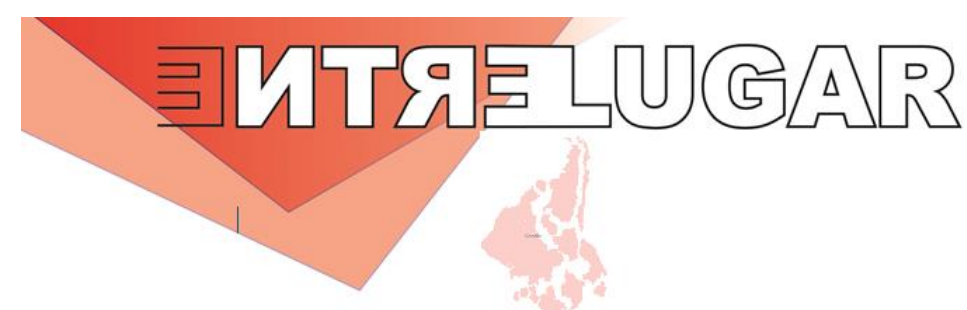

milhão de pares de calçados. Torna-se o nono em pares exportados e o sexto em valor arrecadado. Por sua vez, Pernambuco possui apenas uma empresa exportadora (Alpargatas S.A, em Carpina), que arrecadou cerca de US\$ 8,7 milhões e exportou 4 milhões de pares, sendo o nono em valor arrecadado e o sexto em pares exportados.

Desta forma, as grandes empresas exportadoras chegaram ao Nordeste no âmbito do realinhamento da nova competitividade internacional. As empresas instaladas nos novos territórios são, principalmente, produtoras de materiais sintéticos (tênis, sandálias, botas e outros), o que indica que a produção de calçados de couro, um material tradicional, permaneceu nos centros produtivos antigos. São estes, portanto, que possuem o maior número de micro e pequenas empresas atualmente, enquanto as de maior porte foram relocalizadas para os novos estados da produção.

Neste Sentido, o crescimento considerável do número de vínculos empregatícios formais em estados que compõem o novo mapa da indústria de calçados no Brasil se apresenta como reflexo da ação das maiores empresas através da relocalização de suas etapas produtivas para locais que dispõem de um maior contingente de mão de obra barata, incentivos fiscais e possibilidades de flexibilizar a produção.

As regiões tradicionais sentem o impacto dessa diminuição de empregos, uma vez que as maiores empresas realizam a realocação de unidades produtivas, mas se mantêm entre as maiores exportadoras, tanto em valor arrecadado como em pares exportados. Isso ocorre por meio de novas estratégias, como o aumento do número de contratações, sobretudo através de postos informais, abertos nas últimas décadas. São alterações que podem ser evidenciadas em tradicionais sistemas industriais localizados, como Franca, Birigui e Jaú, no estado de São Paulo; e Sapiranga e Parobé, no Rio Grande do Sul, entre outros municípios. Estes estados, ao tentarem manter a competitividade, fazem uso de bancas ou ateliês informais para completarem cadeias

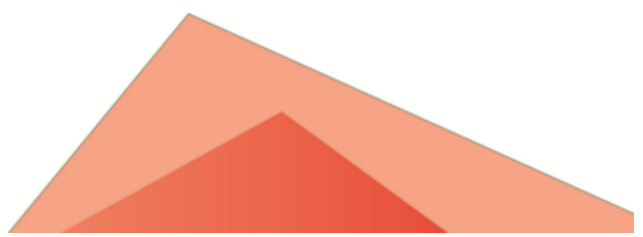




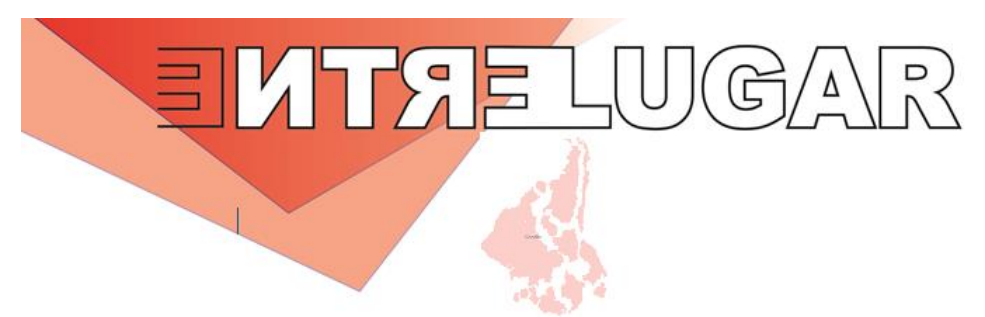

produtivas disjuntivas mais lucrativas, que conformam verdadeiras redes produtivas em escalas locais e regionais.

\section{ALGUMAS CONSIDERAÇÕES}

A indústria calçadista brasileira passa por uma reorganização produtiva constante, uma vez que as empresas buscam flexibilizar a produção no chão de fábrica, na região e no território, dinamizando os circuitos produtivos. O Nordeste do país passa a ser foco da instalação de muitas unidades produtivas e de empresas exportadoras, ligadas aos calçados de material sintético, o que pode ser evidenciado pelo valor médio dos calçados. De igual maneira, os centros tradicionais de produção resistem (principalmente Rio Grande do Sul e São Paulo), mesmo que tenham de incorporar estratégias de reestruturação diferenciadas, sobretudo àquelas ligadas aos processos de disjunção funcional, externalização da produção e outras inúmeras formas de integração produtiva em rede, tributárias de sistemas de trabalho e de tecnologia renovados.

Tais constatações proporcionam ampla leitura dos fenômenos e dos processos ligados à atividade industrial calçadista no contexto da economia política do território no Brasil do século XXI. Contudo, elas não esgotam as possibilidades de interpretação do tema. Pelo contrário, abrem novas perspectivas para investigações que pretendam compreender a relação entre espaço e indústria no âmbito das transformações recentes da economia produtiva e de sua renovação face à competitividade internacional.

Essas constatações preliminares permitem entender que, no bojo das relações entre agentes, ações e formas espaciais, a dinâmica da atividade industrial calçadista no Brasil revela uma eficiente estratégia para introduzir novas relações de produção e trabalho em áreas já consolidadas ou distantes, confirmando que certas formas de acumulação na indústria, quando vinculadas aos valores da competitividade

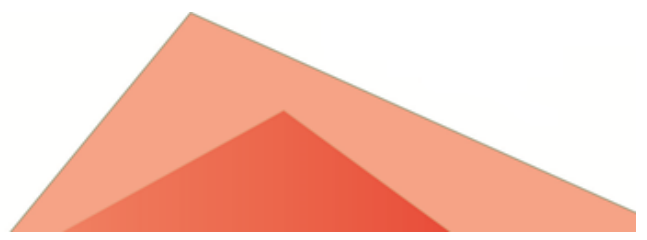




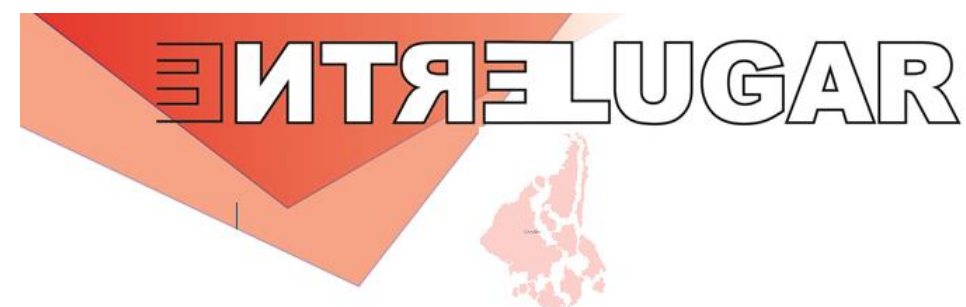

sem limite, podem usar o território e o seu arranjo contínuo ou descontínuo como ferramenta para atender amplas metas de lucratividade.

Aprofundar a investigação de tais mudanças requer atenção, principalmente no que tange às escalas de apreensão da análise e à complexidade das transformações, pois só assim será possível compreender as sinergias do território face ao movimento renovado de interações materiais e imateriais do presente.

\section{BIBLIOGRAFIA}

ABICALÇADOS (Associação Brasileira das Indústrias de Calçados). Resenha estatística. Novo Hamburgo: Abicalçados/Unidade de Inteligência Comercial, 2009.

ABICALÇADOS (Associação Brasileira das Indústrias de Calçados). Indústria de calçados do Brasil. Novo Hamburgo: Abicalçados 2017. Disponível em: $<$ http://www.abicalcados.com.br/index.html>.

ABICALÇADOS (Associação Brasileira das Indústrias de Calçados). Comércio exterior de calçados, exportação. Novo Hamburgo: Abicalçados, 2018a. Disponível em: 〈http://www.abicalcados.com.br/index.html>.

ABICALÇADOS (Associação Brasileira das Indústrias de Calçados). Relatório setorial 2018. Novo Hamburgo, RS. 2018. Disponível em: <http://www.abicalcados.com.br>. Acesso em: 05 maio. 2018b.

ALBUQUERQUE, A. D. A política de industrialização da Paraíba e suas implicações no desenvolvimento local. In: XXIX Congresso latino americano de sociologia ALAS, Santiago do Chile, 2013.

ARROYO, Mónica. Circuitos espaciais de produção industrial e fluxos internacionais de mercadorias na dinâmica territorial do estado de São Paulo. Boletim Campineiro de Geografia, Campinas, SP, v. 2, n. 1, p. 7-26, 2012. Disponível em:<

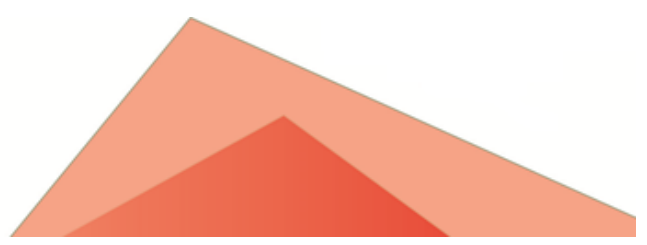




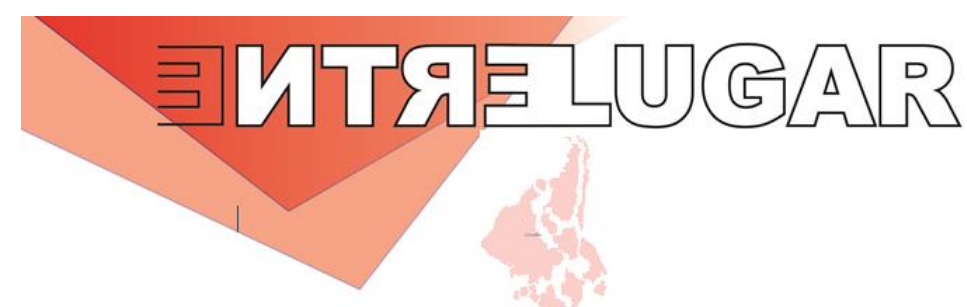

http://agbcampinas.com.br/bcg/index.php/boletim-campineiro/article/view/48/2012-1arroyo>. Acesso em: 27 mar. 2019.

ASSINTECAL. Relatório anual 2017. Novo Hamburgo: Assintecal, 2018.

BAHIA. Secretaria do Planejamento, Ciência e Tecnologia. Superintendência de Planejamento Estratégico. A indústria calçadista na Bahia. Salvador (BA): Superintendência de Planejamento Estratégico, 2000. 120 p.

BARBOSA, Agnaldo de Sousa. Empresariado fabril e desenvolvimento econômico: empreendedores, ideologia e capital na indústria do calçado (Franca, 1920 - 1990). São Paulo: HUCITEC, 2006. 278p.

BRASIL. Ministério do Trabalho e do Emprego. Base de dados estatísticos: RAIS/CAGED. $\quad$ Brasília, 2018. Disponível em:< http://bi.mte.gov.br/bgcaged/login.php>. Acesso em: 18 jul. 2018.

CHESNAIS, François. La prééminence de la finance au sein du "capital en général", le capital fictif et le mouvement contemporain de mondialisation du capital. In: BRUNHOFF, Suzanne et al. La Finance capitaliste. Paris: Actuel Marx: Presses Universitaires de France, 2006. p.65-130.

CICERO, Elaine Cristina. A indústria de calçados de Birigui: origem, reestruturação produtiva e formação de uma economia de aglomeração. Presidente Prudente, 2011. Universidade Estadual Paulista Júlio de Mesquita Filho. 170 p. Dissertação (Mestrado em Geografia).

COSTA, Achyles Barcelos da. Competitividade da indústria de calçados: nota técnica setorial do complexo têxtil. In: COUTINHO, Luciano et al. (Org.). Estudo da competitividade da indústria brasileira. Campinas: Fecamp/MCT/Finep/PADCT, 1993. p. 1-99.

COSTA, Achyles Barcelos da; FLIGENSPAN, Flávio Benevett (Orgs.). O deslocamento das empresas de calçados para o nordeste brasileiro. Porto Alegre: Editora da UFRGS, 2013. p. 144.

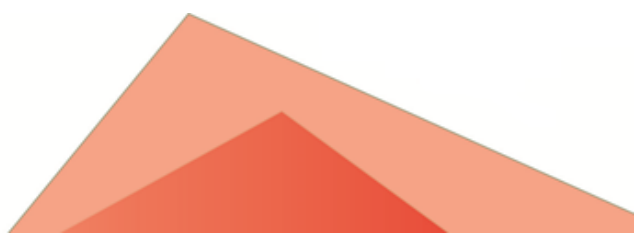




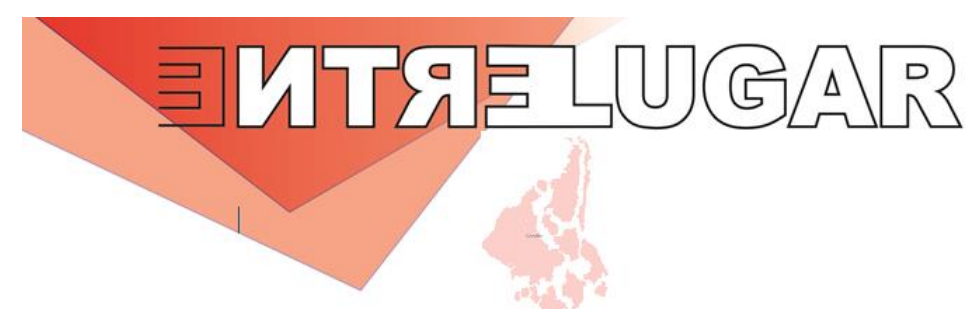

FERREIRA, Marcos. Corporação e geografia: a organização territorial e produtiva do grupo Alpargatas S.A. na Paraíba. Fortaleza: Programa de Pós-Graduação em Geografia da Universidade Estadual do Ceará. Agosto de 2018. p. 174. Dissertação (Mestrado de Geografia).

FISHER, André. Industrie et espace géographique: introduction à la geógraphie industrielle. Paris: Masson, 1994. 137p.

FISCHER, André. Zonas industriais e estratégias econômicas e espaciais. In: FIRKOWSKI, Olga Lúcia Castreghini; SPOSITO, Eliseu Savério. Indústria, ordenamento do território e transportes: a contribuição de André Fischer. São Paulo: Expressão Popular/Unesp - Programa de Pós-Graduação em Geografia, 2008.

MICHALET, Charles- Albert. Mondialisation, la grande rupture. Paris: Éditions La Découvert, 2009.

MOUHOUD, El Mouhoub. Mondialisation et délocalisation des entreprises. Paris: Éditions La Découvert, 2008.

NAVARRO, Vera Lúcia. Trabalho e trabalhadores do calçado: a indústria calçadista de Franca (SP): das origens artesanais à reestruturação produtiva. São Paulo: Expressão Popular, 2006. 304p.

NAVARRO, Vera Lúcia. A reestruturação produtiva na indústria de calçados de Couro em Franca (SP). In: ANTUNES, Ricardo; SILVA, Maria Aparecida Moraes (Orgs.). O avesso do trabalho. São Paulo: Expressão popular, 2004. p. 79-152.

PEREIRA JÚNIOR, Edilson. Território e economia política - uma abordagem a partir do novo processo de industrialização no Ceará. São Paulo: Editora da Unesp/Selo Cultura Acadêmica, 2012.

PEREIRA JÚNIOR, Edilson. A indústria de calçados no Brasil diante da reestruturação territorial e produtiva. In: SPOSITO, Eliseu Savério (Org.). O novo mapa da indústria no início do século XXI: diferentes paradigmas para leitura das dinâmicas territoriais do estado de São Paulo. São Paulo: Unesp Digital, 2015. p. 153-200. 


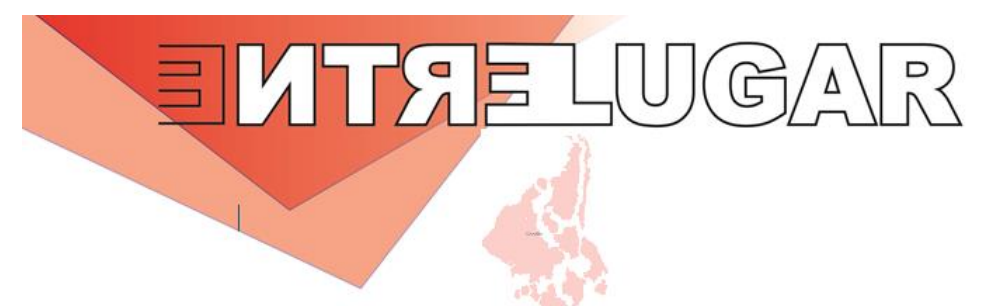

PEREIRA JÚNIOR, Edilson. RODRIGUES, Mateus Almeida. Redes produtivas de calçados e articulação urbano regional - uma análise a partir do estado da Bahia. In: SILVA, Paulo Fernando Jurado da; SPOSITO, Eliseu Savério; SANTANA Mateus Ubirajara Silva (organizadores). Geografia e economia: relações e interfaces. Dourados/MS: Editora UEMS, 2020. p. 78-95.

REIS, Carlos Nelson dos. A indústria brasileira de calçados: inserção internacional e dinâmica interna nos anos 80. Campinas, Instituto de Economia, Universidade Estadual de Campinas 1994. 257 p. Tese (Doutorado em Economia).

RUAS, Roberto. Efeitos da modernização sobre o processo de trabalho: condições objetivas de controle na indústria de calçados. 3.ed. Porto Alegre, FEE, 1986. 168 p.

SAMPAIO, José Eudázio H.. Novas dinâmicas territoriais do sistema industrial localizado calçadista de Franca (SP). Fortaleza: Programa de Pós-Graduação em Geografia da Universidade Estadual do Ceará, fevereiro de 2020. 331p. Dissertação (Mestrado em Geografia).

SAMPAIO, José Eudázio H.; PEREIRA JÚNIOR, Edilson. O sistema industrial localizado de calçados de Franca (SP) e sua nova configuração urbano regional. Espaço e Economia: Revista Brasileira de Geografia Econômica, Rio de Janeiro, 2019.

SAMPAIO, Marcos Guedes Vaz. Industrialização como estratégia histórica de desenvolvimento: reflexões sobre o caso da Bahia. Bahia Análise \& Dados, Salvador (BA), v. 22, n. 2, abr./jun. 2012, p. 303-315.

SANTOS, Milton. Guerra dos lugares. In: SANTOS, Milton (Org.). O país distorcido: o Brasil, a globalização e a cidadania. São Paulo: Publifolha, 2002. p.87-89.

SANTOS, Milton. A natureza do espaço: técnica e tempo, razão e emoção. 4. ed. São Paulo: Universidade de São Paulo, 2004. 260 p.

SANTOS, A. M. M. et al.. Deslocamento de empresas para os estados do Ceará e da Bahia: o caso da indústria calçadista. BNDES Setorial, Rio de Janeiro, n. 15, p. 63-82, 2002.

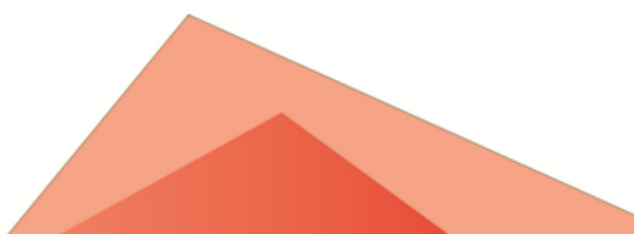




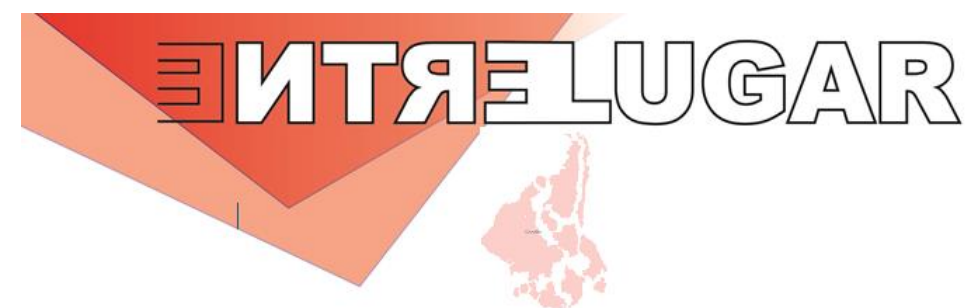

SANTOS, A. M. M.; CORREA, A. R., ALEXIM, F. M. B. A indústria de calçados no estado do Ceará. Rio de Janeiro: BNDES, 2001.

SCHNEIDER, Sérgio. Agricultura familiar e industrialização - produtividade e descentralização industrial no Rio Grande do Sul. $2^{\mathrm{a}}$ ed. Porto alegre: Editora da UFRGS, 2004.

SDE - SECRETARIA DE DESENVOLVIMENTO ECONÔMICO DO ESTADO DE SÃO PAUlO. Polos de Desenvolvimento: Couro e calçados. São Paulo, 2019. Disponível em: < http://www.saopaulo.sp.gov.br/ultimas-noticias/governo-paulistaanuncia-11-polos-de-desenvolvimento-economico/>. Acesso em: $28 \mathrm{dez}, 2019$.

SPOSITO, Eliseu Savério (Org.). O novo mapa da indústria no início do século XXI: diferentes paradigmas para leitura das dinâmicas territoriais do estado de São Paulo. São Paulo: Unesp Digital, 2015.

VELTZ, Pierre. Le nouveau monde industriel. Édition revue et augmentée. Paris: Éditions Gallimard, 2008.

VELTZ, Pierre. La société hyper-industrielle: le nouveau capitalisme productif. Paris: La Republique des Idees/Seuil, 2017.

WORLD SHOE REVIEW. Footwear industry. 2017. Disponível em: < http://www.worldshoereview.co.uk/index.html>. Acesso em: 15 set. 2019.

ZIMMERMANN, Ilaine. A construção da demanda por formação profissional no centro tecnológico de calçado SENAI/Novo Hamburgo para a indústria calçadista. Porto Alegre, Programa de Pós-Graduação em Educação da Universidade Federal do Rio Grande do Sul, 2005. Dissertação (Mestrado em Educação).

Recebido em março de 2020.

Aceito para publicação em abril de 2020.

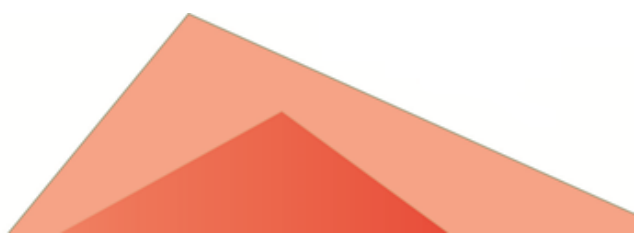

